University of Nebraska - Lincoln

DigitalCommons@University of Nebraska - Lincoln

1988

\title{
Ecology, Behavior, and Distribution of Blattella asahinai (Orthoptera: Blattellidae) in Central Florida
}

\author{
Richard J. Brenner \\ USDA-ARS, Insects Affecting Man and Animals Research Laboratory, P.O. Box 14565, Gainesville, Fla. \\ 32604 \\ R. S. Patterson \\ USDA-ARS, Insects Affecting Man and Animals Research Laboratory, P.O. Box 14565, Gainesville, Fla. \\ 32604 \\ P. G. Koehler \\ Department of Entomology and Nematology, University of Florida, Gainesville, Fla. 32611
}

Follow this and additional works at: https://digitalcommons.unl.edu/entomologyother

Part of the Entomology Commons

Brenner, Richard J.; Patterson, R. S.; and Koehler, P. G., "Ecology, Behavior, and Distribution of Blattella asahinai (Orthoptera: Blattellidae) in Central Florida" (1988). Entomology Papers from Other Sources. 84. https://digitalcommons.unl.edu/entomologyother/84

This Article is brought to you for free and open access by the Entomology Collections, Miscellaneous at DigitalCommons@University of Nebraska - Lincoln. It has been accepted for inclusion in Entomology Papers from Other Sources by an authorized administrator of DigitalCommons@University of Nebraska - Lincoln. 


\title{
Ecology, Behavior, and Distribution of Blattella asahinai (Orthoptera: Blattellidae) in Central Florida ${ }^{1}$
}

\author{
RICHARD J. BRENNER, ${ }^{2}$ R. S. PATTERSON, ${ }^{2}$ AND P. G. KOEHLER ${ }^{3}$
}

\begin{abstract}
Ann. Entomol. Soc. Am. 81(3): 432-436 (1988)
ABSTRACT The Asian cockroach, Blattella asahinai Mizukubo, a close relative of the German cockroach, B. germanica (L.), has been discovered in over $900 \mathrm{~km}^{2}$ from Tampa to Lakeland, Fla., and is prevalent in citrus groves, wooded areas, lawns, and homes. Differentiation of the two species is best accomplished by the diagnostic behavior of the Asian cockroach-it is crepuscular (sunset) and nocturnal, readily flies, is attracted at sunset to light-colored or brightly lit surfaces, and lives outdoors in large numbers. Analyses of microhabitat composition of 86 trap sites indicate that the principal habitat of the Asian cockroach is leaf litter in shaded areas. Here, the densities of nymphs and females bearing oöthecae were highest. All other adults were more diffusely distributed. Asian cockroaches may be difficult to control because of the mobility of the species and the common occurrence of feral reservoirs.
\end{abstract}

KEY WORDS Insecta, Asian cockroach, spatial distribution, habitat

IN FEBRCARY 1986, specimens of a cockroach morphologically similar to the German cockroach, Blattella germanica (L.), were collected at a house in Kathleen, Fla. (9 $\mathrm{km}$ northwest of Lakeland). Although they appeared to be, and could be keyed to, German cockroaches, their behavior was inconsistent with that of German cockroaches; the latter are capable only of gliding flight and occur outside only occasionally and never in large numbers (Cornwell 1968). The cockroach in Kathleen was very abundant in the lawn and readily flew when disturbed. In mid-June, the specimens were identified as Blattella asahinai Mizukubo by Louis Roth, Harvard University, and Takayuki Mizukubo of Japan, who first described the species (Mizukubo 1981). This was the first report of this species, which we call the Asian cockroach, in the Western Hemisphere (Fig. 1).

Blattella asahinai is synonymous with $B$. beybienkoi Roth (Roth 1986), and in the phylogeny of the 45 recognized species in the genus worldwide, $B$. germanica and B. asahinai are most closely related (Roth 1985). Preserved specimens of this species are extremely difficult to separate morphologically from German cockroaches; the shape of the medial longitudinal groove on the eighth abdominal tergite and the tergal gland in males are the only diagnostic characters, and they are difficult to discern. Therefore, it is likely that diagnostic behavioral traits will be the most reliable for the layman or professional pest control operator in distinguishing between these species.

${ }^{1}$ This article reports the results of research only. Mention of a proprietary product does not constitute an endorsement or a recommendation for its use by USDA.

${ }^{2}$ USDA-ARS, Insects Affecting Man and Animals Research Laboratory, P.O. Box 14565, Gainesville, Fla. 32604

${ }^{3}$ Department of Entomology and Nematology, University of Florida, Gainesville, Fla. 32611
We collected both B. asahinai and B. germanica inside the home in Kathleen (identifications by $\mathrm{L}$. Roth). This finding, and reports from other homeowners, confirmed that B. asahinai presents significant problems. Therefore, we initiated studies on its biology and behavior to determine its microhabitat distribution (preferred habitats) on the infested property, so that similar microhabitats at other locations could be surveyed. Here, we report observations and data on the behavior and distribution of this species.

\section{Materials and Methods}

Activity of Asian cockroaches was observed outside the home in Kathleen on numerous occasions during March, April, and May. Temperature, humidity, and light intensity levels were recorded periodically during 24 -h observation periods. Concurrent with observations in mid-April, the microhabitat distribution was studied by sampling the population at 86 ground level sites (Fig. 2). Sites were selected to sample all microenvironments defined by the relative densities of grass $(G)$ and leaf litter (L), and the degree of shading or openness of canopy (S). The area immediately surrounding each trap (30 cm radius) was categorized subjectively into one of three levels for each of the three parameters, low (1), medium (2), or heavy (3). Thus, a particular trap site could receive a score such as G1S3L3. In general, values of 1 reflected an absence of that parameter. One section of the property (northeast corner) contained discarded clothing, furniture, and herbaceous materials (pulled weeds, leaves, and grass clippings). Although technically ground cover, it was classified as leaf litter.

Traps (artificial harborages) were made from two plywood squares ( 15 by 15 by $0.63 \mathrm{~cm}$ ), separated on three sides by strips of balsa wood $(5 \mathrm{~mm}$

This article is a U.S. government work, and is not subject to copyright in the United States. 


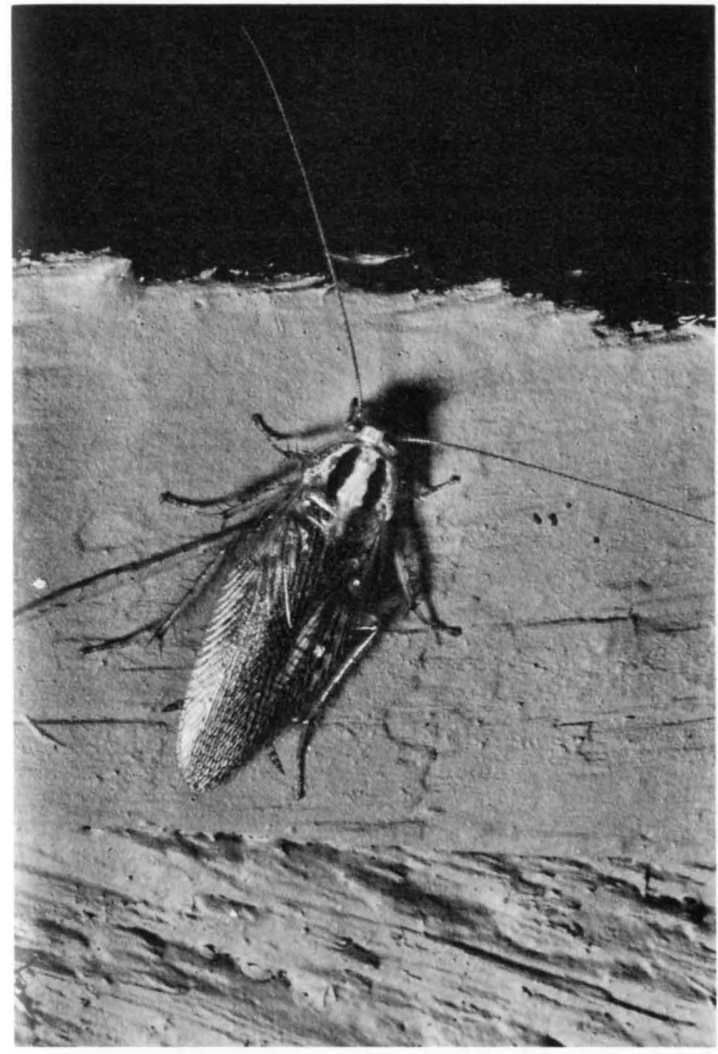

Fig. 1. A female Asian cockroach, Blattella asahinai, perched on the siding of a home.

by $5 \mathrm{~mm}$ by $15 \mathrm{~cm}$ ). The fourth side provided an entrance for the cockroaches. Because central Florida was then undergoing a drought, the inside surfaces of traps were wetted thoroughly to maintain high RH; a small quantity of dry distiller's grain (Brenner \& Patterson in press) was sprinkled inside each trap as an attractant. The entrances of all traps faced west so cockroaches would not be disturbed by the rising sun. The following morning, each trap was placed quickly inside a polypropylene bag where cockroaches were anesthetized with gaseous $\mathrm{CO}_{2}$ and counted.

Numbers of cockroaches per trap were tested for normality according to SAS univariate procedures (SAS Institute 1985a) and found to be skewed significantly (coeff. of skewness $=1.22, P<0.01$ ). Therefore, data were transformed to ranks (Conover \& Iman 1981), and analyzed according to SAS GLM procedures (SAS Institute 1985b). Ranked data were analyzed to determine whether relative densities of grass, shade, or leaf litter (interactions not considered) were predictive for the distribution of Asian cockroaches. Means, in original scale, are reported in tables by microhabitat score, but separation of means was conducted on ranked data using the Waller-Duncan test option (SAS Institute 1985 b). Interactions were then examined by subjecting data to factorial analysis according to SAS

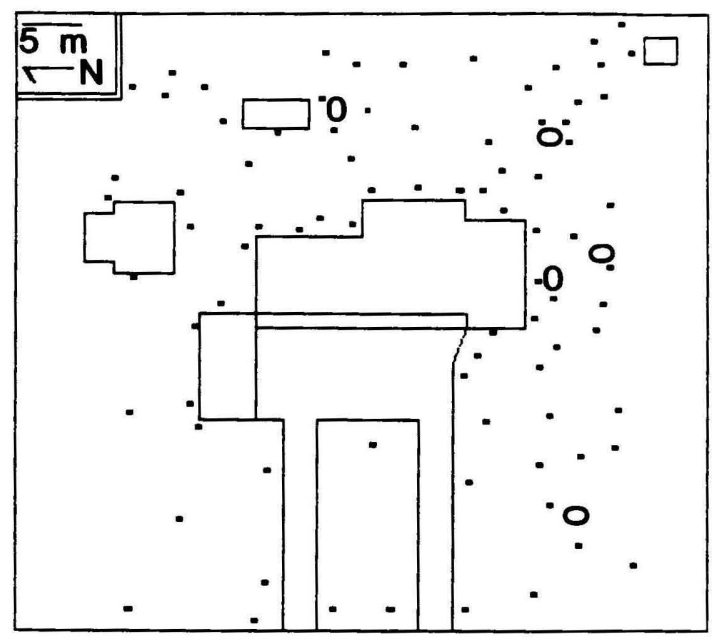

Fig. 2. Schematic representation of the house and structures on the property where Asian cockroaches were first reported in Kathleen, Fla. Small dark squares indicate locations of 85 ground traps used to determine microhabitat distribution. Trees are shown as circles.

GLM procedures; relative densities were considered as continuous variables for the analyses.

Spatial distributions of cockroaches also were estimated through the property using commercially available software programs (Golden Software Inc., Golden, Colo.) called GRID and TOPO. Briefly, GRID estimates population densities throughout the property based on the location of traps and the number captured at each specific location. We wanted estimates at 1-m intervals, which required a 70- by 70-m grid. Thus, population densities were estimated at 4,900 points of intersection. For each estimate, all traps within an arbitrarily selected distance of $25 \mathrm{~m}$ were used to estimate the population at that point using the Kriging algorithm, which assumes a trend (large-scale variation) and a fluctuation (small-scale random process) (Ripley, 1981). The program TOPO utilizes this "gridded" data to construct contour lines of equal population densities. These programs also were used to plot the distribution of grasses, shade, and leaf litter, allowing a visual comparison with contour maps of cockroach distribution.

Voucher specimens of Blattella asahinai have been deposited at the U.S. National Museum of Natural History, Washington, and a request has been made to list "Asian cockroach" in the list of approved common names of insects of the Entomological Society of America.

\section{Results and Discussion}

Because Asian cockroach behavior was remarkably similar throughout the 3-mo observation period, a typical behavior pattern of a 24-h period in April is described here in some detail. Activity of this species can be classified generally as circa- 
dian-crepuscular and nocturnal, with a single peak beginning at sunset. During this period of observations, temperatures ranged from 23.6 to $15.2^{\circ} \mathrm{C}$ and $\mathrm{RH}$ varied from 38 to $63 \%$. In the following description of activity, all times are relative to official occurrence of sunset or sunrise, listed in the Nautical Almanac (U.S. Naval Observatory, Washington) at this latitude as 1856 and 0601 hours, respectively.

Thirty min prior to sunset, light intensity was 100 foot-candles ( $\mathrm{fc}$ ); little activity was apparent. At sunset, light intensity had diminished to $10 \mathrm{fc}$, and adults began coming from leaf litter and crawling to the tips of weeds and blades of grass, commonly flying $1-3 \mathrm{~m}$. At $10 \mathrm{~min}$ after sunset, males were seen flying onto light-colored walls; females followed within minutes. By 20 min after sunset, flying adults were abundant, and they were attracted to the light of a flashlight. Although flight to areas illuminated by incandescent lights was common, adults apparently were not attracted to the mercury-vapor yard light, nor to a white sheet illuminated by a portable long wave ultraviolet light. Flights of over $30 \mathrm{~m}$ were common. Adults were abundant on a white wall-two were within $10 \mathrm{~cm}$ of the ground, 14 were between 10 and 35 $\mathrm{cm}, 14$ were between 35 and $56 \mathrm{~cm}$, and three were above $56 \mathrm{~cm}$. A red wall only $10 \mathrm{~m}$ away was without cockroaches. Adults and nymphs were common on vegetation $30 \mathrm{~min}$ after sunset. Activity peaked at this time, with adults and nymphs crawling on mulch, vegetation, and lawn furniture.

Behavior had changed noticeably by $45 \mathrm{~min}$ after sunset. Most adults had moved from the wall, although a few, and some nymphs, remained. Many adults of both sexes, including females with oöthecae, were motionless on vegetation; no flying adults were observed. At 60 min after sunset, most cockroaches were feeding on organic debris and dead insects; approximately 35 adults (no nymphs) were seen feeding on honeydew of aphids in an infested citrus tree. Only two cockroaches (females) were seen on walls at 75 min after sunset. Nymphs and adults were seen feeding or sitting motionless on vegetation; this activity continued throughout the night.

Behavior again changed beginning $100 \mathrm{~min}$ before sunrise, when one copulating pair was observed on vegetation. Temperature was at a minimum of $15.2^{\circ} \mathrm{C}$. At $75 \mathrm{~min}$ before sunrise, nymphs and adults began descending vegetation and returned to leaf litter. Fifty minutes before sunrise, the copulating pair separated; no cockroaches were apparent in the grass nor on vegetation-activity was at a minimum.

During these months, observations at other homes in the area indicated that adults sat on the outside walls near lighted lamps and on window screens of lighted rooms. As long as lights were lit, adults remained on the walls; however, once lights were extinguished ( $1-2 \mathrm{~h}$ after sunset), adult cockroaches left the walls. We also observed Asian cockroaches inside occupied homes; adults were attracted to lighted rooms, flying about the room and landing on television screens or illuminated walls, tables, and dishes. Hence, once they have entered a home, their presence becomes obvious. Cockroaches that gained entrance in the evening often were found the following morning under damp towels, rags, and sponges, as well as in potted plants. On occasion, adults were taken from kitchen cabinets, but large numbers were not found. Based on comments and attitudes of homeowners, their tolerance threshold is zero-one Asian cockroach is too many.

The board traps captured a total of 748 cockroaches during the night of 16 April (133 males, 438 females, and 177 nymphs). Mean $( \pm \mathrm{SE})$ percentages per trap by stage were $16.9 \pm 2$ for males, $63.8 \pm 3$ for females, and $19.4 \pm 2.5$ for nymphs; 85 females (19.4\%) carried oöthecae. Counts from four sticky traps (Zoecon Corp., Dallas, Tex.) placed on the property for $24 \mathrm{~h}$ yielded percentages of $29 \pm 6,42 \pm 1.6$, and $29 \pm 7.4$, respectively, for males, females, and nymphs; 3 of 66 females (4.5\%) carried oöthecae.

Separate analyses of effects of grass, shade, or leaf litter are presented in Table 1. The numbers of females bearing oöthecae (hereafter referred to simply as oöthecae) were not significantly different when grouped according to relative densities of grass or degree of shade. However, all three means differed significantly when data were categorized by degree of leaf litter; the mean number of oöthecae was highest where leaf litter was most abundant. Mean numbers of adults per trap increased in proportion to quality of the environment. Means in all three categories grouped by density of grasses were significantly different. When traps were grouped by degree of shade or abundance of leaf litter, means were always highest in category 3 , but these values were not significantly different from those in category 2 . These data suggest that all three parameters are important in predicting distribution of the Asian cockroach, and increasing cover and shade generally result in more of them being captured.

All parameters and their interactions were examined as continuous variables; a summary is presented in Table 2. Because of the significance of leaf litter (Table 1), and the obvious relationship of trees (shade) and leaves, all analyses included the variables in the order of leaf, grass, and shade, and all models were highly significant in predicting distribution of Asian cockroaches. For females bearing oöthecae, the continuum of leaf litter clearly was the most significant in describing distribution $(P=0.0001)$, but shade also was significant $(P=0.05)$. The distribution of adults was predictive by all three parameters, and the interaction of grass and shade was nearly significant $(P=0.06)$. For nymphal stages, relative densities of leaf and grass were highly significant in describing the distribution; shade was less predictive but still strongly significant $(P=0.01)$, as was the interaction of leaf 
Table 1. Mean numbers of cockroaches per trap categorized by degree of grass, shade, or leaf litter (1, low; 2, medium; 3, high) in the vicinity of each trap; numbers in parentheses are number of traps in each category ${ }^{a}$

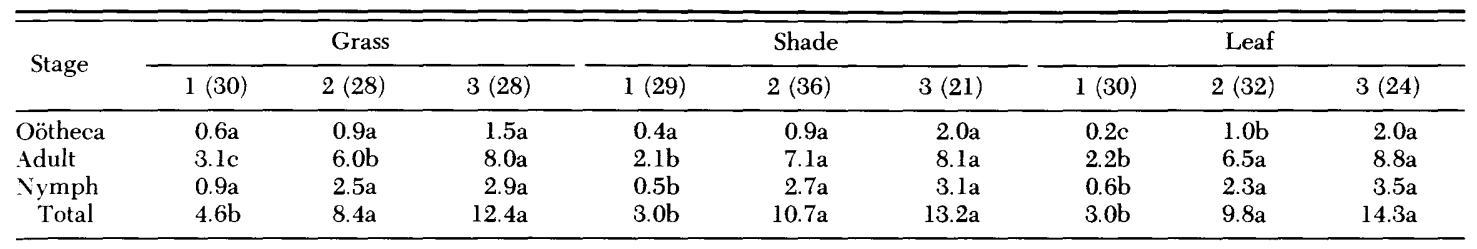

${ }^{a}$ Analyses by category (grass, shade, leaf) are mutually exclusive; three analyses are presented. Means within a row for each category followed by the same letter are not significantly different $(P>0.05$; Waller-Duncan multiple range test [SAS Institute 1985b]).

and grass $(P=0.05)$. When the total population of Asian cockroaches is considered, leaf litter, grass, shade, and leaf-grass interactions are most significant.

We therefore conclude that leaf litter represents the principal focus (that is, microhabitat) for the development of Asian cockroaches. Only levels of leaf litter were highly significant in describing the distribution of females bearing oöthecae, indicating that leaf litter is the preferred site for deposition of oöthecae about to hatch. Nymphs were most abundant where leaf litter was heavy, where grass was thick, or where there was some combination of the two. The distribution of adults (oöthecabearing females excluded), clearly the most mobile stage, was diffuse; distributions were clearly related to leaf litter, but the interaction of grass and shadenot necessarily associated with leaves-was nearly significant in describing their distribution. Thus the most mobile stage of the species is not restricted to leaf litter. This could present serious problems for homeowners on a local basis, and for nearby communities currently not within the known area of infestation.

Spatial distributions are plotted as contours of equal densities of grass, shade, and leaf litter in Fig. 3 a-c. As expected from the data in Tables 1 and 2 , shade and leaf litter had similar distributions. The area of leaf litter in the upper left corner of the plot, the trash pile containing old clothing, discarded furniture, and discarded herbaceous material, did not correlate with the occurrence of shade. The focality of oötheca-bearing females can be visualized by comparing their distributions to those of other adults and nymphs. Fig. $3 \mathrm{~d}-\mathrm{f}$ shows that females with oöthecae were highly focalized and coincident with leaf litter. Nymphs were slightly more diffuse, but their distribution appeared to correlate with the occurrence of shade and grass. In contrast, the distribution of males and nonoöthecal-bearing females was diffuse, and although concentrated in grassy areas of shade and leaf litter, many were taken in areas with little growth of grass.

Based on these findings, we examined 26 other similar sites in an area of $70 \mathrm{~km}^{2}$ surrounding the home in Kathleen. Asian cockroaches were found at 13 of these locations. Populations were well established in citrus groves that had been damaged by the severe winters of 1983 and 1984. Consequently, groves normally maintained free of leaf litter and undergrowth, and frequently treated with various pesticides, were abandoned and had become overgrown with grasses, providing a suitable habitat for Asian cockroaches.

Moreover, in late June, Asian cockroaches were reported $45 \mathrm{~km}$ west southwest of Kathleen in suburbs of Tampa. Large numbers of nymphs and flying adults were found in several neighborhoods. In a subsequent survey involving 3 - to 5-min inspections of leaf litter along roadsides (away from houses), Asian cockroach nymphs and flying adults were found at 17 of 18 sites covering an area of $165 \mathrm{~km}^{2}$ extending to the port of Tampa, a likely point of introduction. Ecological studies at three heavily infested properties in July and August con-

Table 2. $F$ statistic (upper number) and probability levels (lower number) for general linear models (SAS Institute 1985b) describing the distribution of Asian cockroaches at a site in Kathleen, Fla., according to degree of leaf (L), grass (G), and shade (S), and for interactions of these variables; degrees of freedom for the analyses are listed in parentheses below the variable designation

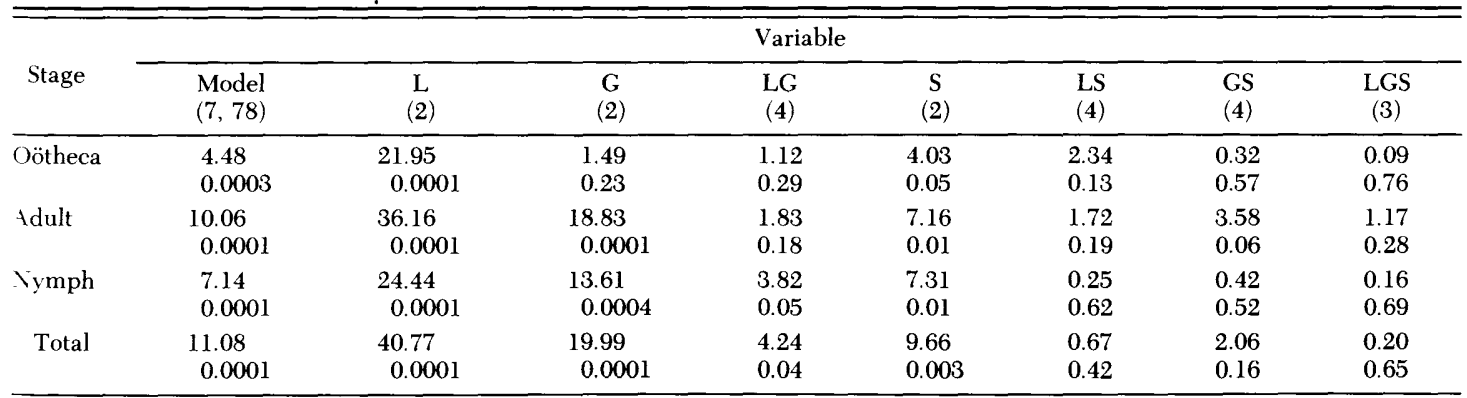




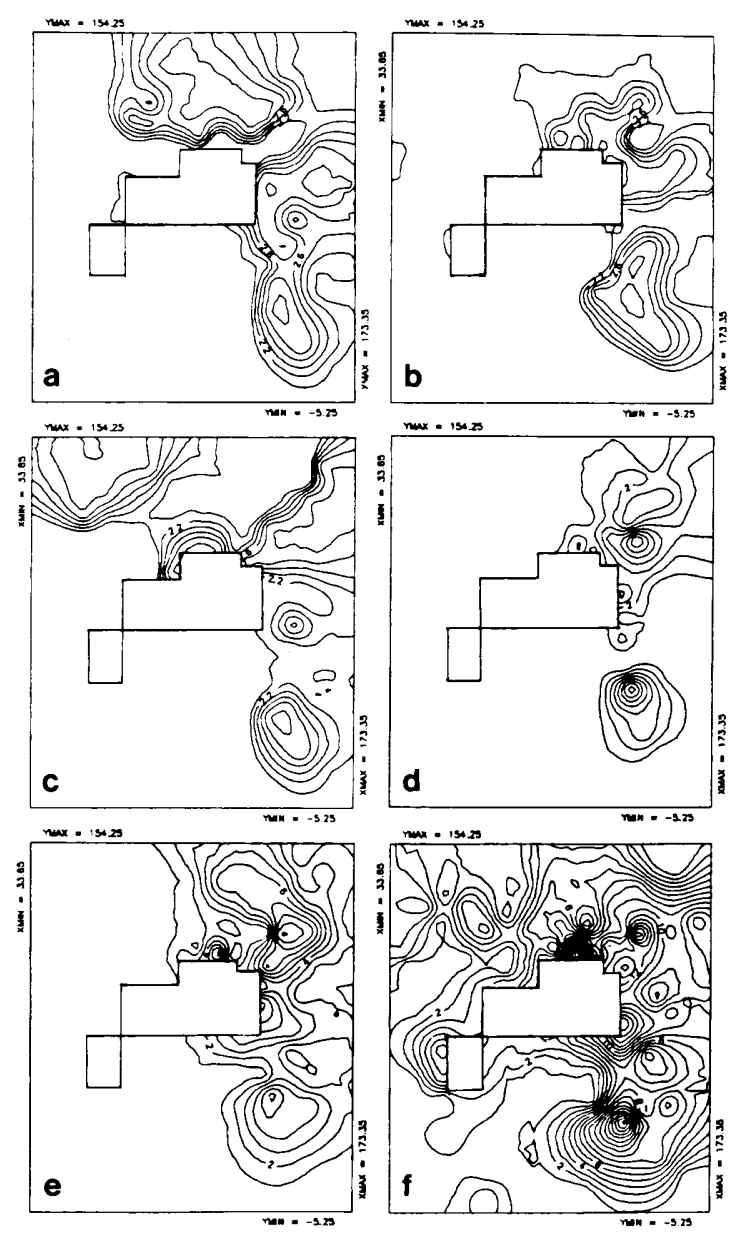

Fig. 3. Visual comparison of microhabitat parameters and life stages of the Asian cockroach relative to the house in Kathleen, Fla. (16 April 1986). Contour maps of the distribution of grass (a), shade (b), and leaf litter (c) display lines of equal density. Contours less than 2 have been suppressed for clarity because values of 1 indicate absence of the character. Spatial distributions of Asian cockroaches are shown as contour maps of equal densities (life stage per trap) of females bearing oöthecae (d), nymphs (e), and adults excluding females with oöthecae (f). These contours are at intervals of 1 . See Fig. 2 for location of traps and trees.

firmed our findings in Kathleen; populations were greatest in shaded areas of leaf litter, where females bearing oöthecae were most concentrated.
Based on these observations, we estimate that the Asian cockroach is firmly established in at least $900 \mathrm{~km}^{2}$ of central Florida in portions of Hillsborough, Polk, and Pinellas Counties. Because feral reservoirs are common, and because Asian cockroaches are strong fliers and photopositive at sunset, long-term control of this species may be difficult to achieve.

\section{Acknowledgment}

The authors thank Ed Shower and Bob Broyles of McArthur Pest Control in Lakeland, Florida, for the primary submission of specimens, and for their field as. sistance in Kathleen. Thanks go to L. Roth and T. Mizukubo for their diligent efforts in identifying the species. We also thank B. Hileman, Winter Haven, Florida, for permission to work on the property in Kathleen. Special thanks are extended to M. McKinney and especially J. Hinton, Hillsborough County Cooperative Extension, for their cooperation and invaluable assistance in the Tampa area. The photograph (Fig. 1) was provided by R. Bjork, U.S. Department of Agriculture Information Service. This publication is Florida Agricultural Experiment Station Journal Series No. 7996.

\section{References Cited}

Brenner, R. J. \& R. S. Patterson. In press. Efficiency of a new trapping and marking technique for peridomestic cockroaches. J. Med. Entomol.

Conover, W. J. \& R. L. Iman. 1981. Rank transformation as a bridge between parametric and nonparametric statistics. Am. Statistician 35: 124-129.

Cornwell, P. B. 1968. The cockroach, vol. 1. Hutchinson, London.

Mizukubo, T. 1981. A revision of the genus Blattella (Blattaria: Blattellidae) of Japan. I. Terminology of the male genitalia and description of a new species from Okinawa Island. Esakia 17: 149-159.

Ripley, B. D. 1981. Spatial statistics. Wiley, New York.

Roth, L. M. 1985. A taxonomic revision of the genus Blattella Caudell (Dictyoptera, Blattaria: Blattellidae). Entomol. Scand. Suppl. 22.

1986. Blattella asahinai introduced into Florida (Blattaria: Blattellidae). Psyche 93: 371-374.

SAS Institute. 1985a. SAS procedures guide for personal computers, version 6 ed. SAS Institute, Cary, N.C.

1985b. SAS/STAT guide for personal computers, version 6 ed. SAS Institute, Cary, N.C.

Received for publication 23 July 1987; accepted 25 September 1987. 